\title{
The XLVII ISCEV International Symposium Abstract Issue
}

\author{
Alma Patrizia Tormene
}

Published online: 21 August 2009

(C) Springer-Verlag 2009

The 47th Annual Congress of the ISCEV will be held this year in Italy, at Padova-Abano Terme.

Padova is an ancient town, founded long before the Romans came and built their city, the remains of which can still be seen. Today, its picturesque medieval heart still pulses with life and energy. The University, one of the oldest in Europe, but modern in its endeavours, helps to give the town a youthful and dynamic air.

Nearby Abano Terme, where most of the scientific sessions will occur in the Congress Centre Pietro d'Abano, is an elegant spa town, lying at the foot of the pleasing Colli Eugani (Euganean Hills).

The meeting will be marked by its high level of scientific content and by a busy round of social activities.

This year the Keynote Lecture of the symposium will be given by Prof. Lamberto Maffei-former director of the National Institute of Neurosciences of the CNR and Professor di Neurobiology at the University of Pisa "Scuola Normale Superiore di Pisa"-who will speak on the "Environmental effect on cerebral function".

Prof. Edoardo Midena, director of the Ophthalmic Clinic of the University di Padova, and Invited Lecturer will deal with "Injecting the eye: Neurosensory retina and intravitreal drugs for degenerative retinal diseases". Furthermore a Special session

A. P. Tormene ( $\bowtie)$

Dipartimento di Neuroscienze, Clinica Oculistica,

Università di Padova, Padova, Italy

e-mail: alma.patrizia.tormene@unipd.it di genetics has been organized, where Dr Enrico Surace-Assistant Investigator of the Telethon Institute of Genetics and Medicine of Napoli-will speak on the "Development of retinal gene therapy: strategies for translational research".

The authoritative Adachi Lecture will be given by Prof. Guenter Niemeyer in the prestigious and historic Aula Magna (Great Hall) of the University of Padova.

The main topics of the Symposium are: "Non standard stimuli-their contributions to modern electrophysiology" and "New therapies-from photoreceptors to glaucoma".

As well as the sessions dedicated to the main topics there will also be sessions on: Clinical Electrophysiology, Pediatrics, Animal models, Imaging, two informative poster sessions and lively discussions of Clinical Cases.

Many applications were sent in for the Eberhard Dodt Award which reveals a high level of participation among young researchers working in the field of ocular and visual pathway electrophysiology. The large number of travel grants offered by the ISCEV also shows how the association is aware of the needs of its members.

There will also be a rich program of events especially laid on for the guests who accompany participants all of which offers firm proof of the spirit that animates ISCEV and encourages not only a fruitful exchange of scientific ideas but also a cultural exchange all of which helps, and has helped, to foster lasting friendships between participants. 